cancer found. European studies have indicated positive predictive values ranging from $30 \%$ to $60 \%{ }^{15}$ These figures represent the positive predictive value of screening in all age groups. If women below the age of 50 were considered alone, the incidence of false positive results would probably be higher. Besides the disfigurement caused by unnecessary biopsies, the period of uncertainty is very stressful for the women and their families.

cost

All health services are looking for ways to contain costs. Resources must be spent on proved treatment and preventive care. As no evidence exists to support the efficacy of mammographic screening in women under 50 it is unreasonable to ask for public support. In the United States the cost to society of screening women aged $40-50$ will be over $\$ 402$ million by the year $2000 .{ }^{16}$

Even if we accept the results of the Health Insurance Plan study and assume a $25 \%$ relative reduction in mortality from breast cancer this translates to only a $0.125 \%$ absolute reduction in deaths, which means that one life would be saved for every 1250 women screened. One radiation induced cancer caused by 12500 mammograms over 10 years would wipe out this small benefit as would one suicide or treatment related death per 1250 women screened.

\section{Informed consent}

A compromise between the recommendations of the European Society of Mastology and the American Cancer Society would be to obtain informed consent before screening. In their discussion of the value of screening mammography in women below 50 Eddy $e t$ al commented: "existing evidence does not justify the conclusion that failure of an individual physician or organisation to recommend or cover mammography is bad medical practice or constitutes malpractice." ${ }^{16}$ If anything, the reverse is true-advocating mammography for younger women without obtaining proper informed consent, including the potential for harm as well as for benefit, must be considered negligent. These same standards must also be applied to women who obtain screening mammograms in the private sector. If it is not appropriate to screen younger women in a national programme then it is not ethical to screen them privately without first obtaining informed consent.

1 European Society of Mastology Consensus Panel. Consensus statement. The Breast (in press)

2 Payer L. Medicine and culture. London: Victor Gollancz, 1989.

3 Stacey-Clear A, McCarthy KA, Hall DA, Pile-Spellman E, White G, Hulka C et al. Breast cancer survival among women under age 50: is mammography detrimental? Lancet 1992;340:991-4.

4 Miller AB, Baines CJ, To T, Wall C. Canadian national breast screening study. 1. Breast cancer detection and death rates among women aged 40 to 49 years. Can Med Assoc f 1992;147:1459-76.

5 Miller AB, Baines CJ, To T, Wall C. Mammography. Lancet 1993;341:439.

6 Shapiro S, Venet W, Strax P, Venet L. Periodic screening for breast cancer: the Health Insurance Plan project and its sequelae, 1963-86. Baltimore: John Hopkins University Press, 1988.

7 Andersson I, Aspergren K, Janzon L, Landberg T, Lindholm K, Linell F, et al. Mammographic screening and mortality from breast cancer: the et al. Mammographic screening and mortality from breast

8 Tabar L, Fagerberg CJG, Gad A, Baldetorp L, Holmberg LH, Grontoft O, et al. Reduction in mortality from breast cancer after mass screening with mammography. Lancet 1985; ;:829-32.

9 Roberts MM, Alexander FE, Anderson TJ, Chetty U, Donnan PT, Forrest P, et al. Edinburgh trial of screening for breast cancer: mortality at seven years. Lancet 1990;335:241-6.

10 Nystrom L, Rutqvist LE, Wall S, Lindgren A, Lindqvist M, Ryden S, et al. Breast cancer screening with mammography: overview of Swedish randomised trials. Lancet 1993;341:973-8.

11 Breast cancer screening in women under 50. Lancet 1991;337:1575-6.

12 Bauer TL, Pandelidis SM, Rhoads JE, Owens RS. Mammographically detected carcinoma of the breast. Surg Gynecol Obstet 1991:173:482-6.

13 Nielsen $M$, Thomsen $\mathrm{L}$, Primdahl S, Dyreborg U, Andersen JA. Breast cancer and atypia among young and middle-aged women: a study of 110 medicolegal autopsies. Brf Cancer 1987;56:814-9.

14 Swift M, Morrell D, Massey RB, Chase CL. Incidence of cancer in 161 families affected by ataxia-telangiectasia. $N$ Engl $₹$ Med 1991;325:1831-6.

15 Reidy J, Hoskins $O$. Controversy over mammography screening. $B M \mathfrak{T}$ 1988;297:932-3.

16 Eddy DM, Hasselblad V, McGivney W, Hendee W. The value of mammo graphy screening in women under age 50 years. $¥ A M A$ 1988;259:1512-9.

(Accepted 22 September 1993)

\title{
Clinical analysis of 100 medicolegal cases
}

\author{
Graham Neale
}

\section{Abstract}

Objective-To find the reasons for legal claims against hospital doctors.

Design-Prospective analysis of requests for medical opinion submitted by solicitors during 1984-93 on legal claims against hospital doctors.

Subjects-100 successive cases: 98 from the United Kingdom and two from the Republic of Ireland.

Main outcome measures-Principal underlying causes of claims.

Results-In 44 cases there was no serious clinical error. Of the 56 cases of clinical fault, seven were a failure of communication by doctors, 15 were an isolated error in otherwise good clinical management, 21 were errors that might not have occurred with better control of clinical practice (doctors exceeding their competence, poor clinical judgment, and poor teamwork), and 13 were major errors due to carelessness or incompetence. In $\mathbf{3 4}$ cases there was evidence of clinical fault that might escape clinical audit and medicolegal processes. Most of these legal claims have been or are likely to be withdrawn: only five plaintiffs have settled out of court, and 11 are pursuing their actions.

Conclusions-To reduce the incidence of errors, hospital doctors should consult colleagues about difficult cases and specialists should maintain a broad interest in disease. The NHS clinical complaints procedure should be extended to cover potential claims, and serious cases should be subject to independent external assessment by experienced consultants.

\section{Introduction}

Over the past five years patients' organisations have become increasingly vocal in their demands for greater flexibility in the handling of clinical complaints against hospital doctors. In particular, they wish to make it easier for the complainant to determine what went wrong, to improve the handling of formal complaints, and to change the present medicolegal system, which is perceived to be expensive and loaded in favour of the defendants. ${ }^{12}$

The medical profession has not ignored the problem and has offered cautious support for the development of some form of no fault compensation..$^{23}$ Nevertheless, except in limited areas (the confidential enquiries into perioperative deaths $s^{4}$ and maternal deaths $s^{5}$, it has not addressed the more important issues of determining the epidemiology of medical accidents, assessing causative factors, and applying this knowledge to reducing the incidence of harmful episodes. The
Graham Neale, consultant physician 
medical defence organisations have expressed their data largely in terms of negligence admitted or proved. Many cases, however, are not pursued for various reasons: solicitors may be unable to determine the truth or may be unable to find supportive doctors; incompetent and inexperienced solicitors may allow cases to drift; barristers may advise that a case, although apparently good, will prove too difficult to fight in court; or solicitors may find liability but not causation, or liability and causation but a likely financial compensation too small to warrant further action.

To date there has been no detailed British study of the epidemiology of medical accidents, although this was suggested three years ago. ${ }^{6}$ Until such a study is undertaken there is a need for data from small scale studies. This paper documents the results of a prospective analysis of 100 claims against hospital doctors unbiased by the result of medicolegal action.

\section{Methods}

I analysed 100 successive requests for a medical opinion on legal claims against hospital doctors submitted to me by solicitors between 1984 and 1993 (98 cases were from the United Kingdom and two from the Republic of Ireland). I received the full case notes together with general practitioners' records, correspondence, and statements from patients and relatives. I assessed each case on the written evidence and produced a report describing what happened as far as this could be determined and as objectively as possible. In producing a commentary on an individual case, I frequently discussed the evidence with other doctors.

For the purposes of this study, cases have been classified according to the circumstance in which the alleged accident occurred and the nature of the mishap. I have paid particular attention to cause in order to make some suggestions for improving clinical practice and limiting the need for medicolegal action.

\section{Results}

Initially there was a steady flow of requests at a rate of just over seven each year, but this has risen to 20 a year since 1991. Requests have come from all over the United Kingdom and the Republic of Ireland, and there has been no significant geographical or hospital bias. The cases reflect my special interest in gastroenterology and general medicine, but the incidents occurred in medical, surgical, gynaecological, and radiotherapeutic units. At the time of the incident (or when the patient or relative became aware of a possible mishap) the age of the patient ranged from 3 months to 90 years with a mean of 47 years. There were 50 female patients and 50 male. In the cases of the 27 patients who died relatives either initiated or continued the medicolegal action. Relatives were also responsible for starting actions on behalf of three children, four elderly people, and two patients who were neurologically damaged.

The requests for a report were received from three months to 11 years (mean 31 months, median 22 months) after the alleged mishap became apparent. Only 25 were within one year of the event, and 24 were delayed by more than three years. In all cases a report was delivered to solicitors within four weeks of the request, although in some cases requests for further information delayed a final assessment to a maximum of three months. Usually it was not difficult to make an apparently reasonable clinical assessment (table I) but it was often difficult to translate this into medicolegal terms: so far five plaintiffs have arrived at a settlement out of court and 11 are pursuing their actions, but most cases have been or are likely to be withdrawn (table II).
TABLE I-Principal underlying causes of 100 claims of negligence against hospital doctors. Figures are numbers of cases

Clinical practice acceptable

Patient or relative unable to accept natural course of disease

process or risk of procedure

Patient or relative showing poor understanding of disease process

Patient or relative unreasonable Clinical fault

Failure of communication by clinical staff

Isolated clinical or surgical error in otherwise good management

Clinical or surgical error in context of doubtful medical practice:

Clinician exceeded competence

Poor judgment

Poor teamwork

Carelessness or major incompetence

TABLE II-Outcome of 100 legal claims against hospital doctors. Figures are numbers of cases

\begin{tabular}{lcccc}
\hline & $\begin{array}{c}\text { Compen- } \\
\text { sation } \\
\text { agreed }\end{array}$ & $\begin{array}{c}\text { Case } \\
\text { ongoing }\end{array}$ & $\begin{array}{c}\text { Case } \\
\text { dormant }\end{array}$ & $\begin{array}{c}\text { Case } \\
\text { withdrawn }\end{array}$ \\
\hline Anderlying cause of claim & 0 & 1 & 5 & 38 \\
Poor communication & 0 & 0 & 1 & 6 \\
Isolated error & 0 & 1 & 8 & 6 \\
Competence exceeded & 0 & 2 & 1 & $2^{\star}$ \\
Poor judgment & 0 & 1 & 2 & 0 \\
Poor team work & 1 & 1 & 6 & 5 \\
Carelessness or incompetence & 4 & 5 & 2 & 2 \\
\hline
\end{tabular}

* One case went to court and plaintiff lost.

CAUSE OF CLAIM FOR NEGLIGENCE: CLINICAL PRACTICE ACCEPTABLE

In 44 cases there was no serious clinical error, and the doctors involved appeared to have made reasonable attempts to explain the course of the illness to the patients and relatives.

\section{Inability to come to terms with disease or end result}

In 21 cases the claimant appeared unable to accept the consequences of the illness. In this category seven patients had malignant neoplasia (of the stomach (two), pancreas, small intestine, colon, metastatic carcinoid tumour, and lymphoma complicating cirrhosis) for which it was claimed that diagnoses were delayed for periods of six weeks to six months. In all cases the doctors had followed a logical diagnostic pathway-for example, a metastatic carcinoid tumour causing flushing in a woman aged 41 was initially diagnosed by a gynaecologist as menopausal symptoms; and increasing ascites in a patient with known cirrhosis was thought to be due to hepatic decompensation rather than complicating lymphoma. Three cases were due to recognised hazards such as endoscopic perforation of cancer of the oesophagus, and in four cases surgical intervention failed to cure the original symptoms (for example, abdominal pain after a gastric reconstruction) or produced a new problem such as incisional hernia. Three patients presented difficult diagnostic problems (volvulus of stomach, volvulus of small intestine, and an infant with Alagille's syndrome), and two patients had complex illnesses in which it was difficult to disentangle organic from psychogenic complaints.

\section{Lack of understanding of disease process}

In 16 cases the patients did not understand the pathology underlying their disease. Six patients did not understand the natural course of their illness (for example, the recurrence of pancreatitis or of rectal prolapse despite the best efforts of doctors). Five patients did not understand the nature of causality (for example, that diverticulitis is not due to the taking of a drug). The remaining five claimants seemed not to have understood that most interventional procedures carry some risk such as a subphrenic abscess after gastric surgery. From the notes of these cases it appeared that doctors had made reasonable attempts to explain the nature of the disease processes, but the 
patients' statements and the questions posed by their legal advisers showed that certain basic principles had not been grasped. Four of the cases were complex, and there was considerable room for misunderstanding.

\section{Unreasonable medicolegal action}

Seven claims appeared to be unreasonable. For example, a woman with persistent, low grade pancolitis was treated intermittently with conventional doses of corticosteroids and long term sulphasalazine. After two to three years without prolonged remission, colectomy was suggested as a therapeutic option, but, because of her poor social circumstances and after discussion, it was considered inappropriate. Although her colitis settled, she was plagued with minor ills that led in nine years to over 400 recorded visits to her general practitioner. She developed musculoskeletal symptoms and subsequently read a magazine article on steroid induced osteoporosis and considered that she had cause to sue the clinicians who had treated her in the first instance.

CAUSE OF CLAIM FOR NEGLIGENCE: FAULTS IN CLINICAL PRACTICE

In 56 cases clinicians were judged to be at fault. These faults have been categorised according to their nature.

\section{Failure of communication}

In seven cases the problems were primarily those of communication. In five there were failures to warn patients of the risks of clinically justified procedures (colonoscopy, endoscopic retrograde cholangiopancreatography, dilatation and curettage, abdominal surgery, and radiotherapy). In a sixth case a clinician and a radiologist argued in front of a patient about failing to diagnose duodenal ulceration at endoscopic examination. Finally, an orthopaedic surgeon failed to act on a patient's warning that she was likely to become seriously constipated after surgery. During her convalescence she required repeated manual evacuations and subsequently developed an anal fissure.

\section{Chance error during otherwise careful practice}

In 15 cases diagnosis was delayed or a procedural error was made, although otherwise management was satisfactory. The 10 cases of diagnostic difficulty were for Crohn's disease (two cases), recurrent intestinal obstruction due to adhesions, duodenal ulcer missed at endoscopy (the patient bled to death one week later), gallstones misdiagnosed as ischaemic heart disease, pancreatitis misdiagnosed as gastroenteritis, intestinal infarction, cancer of the stomach, dumping syndrome after gastric surgery, and pulmonary embolism after major surgery.

\section{Error in context of poor clinical practice}

There were 21 cases of clinical error that might not have occurred with better controlled practice.

Doctors exceeding their competence-In four cases non-consultant clinicians undertook endoscopy on their own and perforated a normal gut. In another case a senior house officer was given inadequate instruction on how to remove a transcutaneous feeding tube.

Poor clinical judgment-Three cases were due to flawed clinical judgment in specialist units. Two patients were advised to undergo endoscopic retrograde cholangiopancreatography without careful assessment. Neither had pancreatic or biliary pathology, and both developed life threatening pancreatitis. In the third case a surgeon allowed his clinical judgment to override the implications of a histopathological report, and the patient underwent an unnecessary laparotomy

Poor teamwork - In 13 cases there was evidence of inadequate care by more than one member of a clinical team. In six patients the severity of the illness was unrecognised. For example, a patient was admitted to hospital with severe Crohn's disease. Despite conventional treatment her condition deteriorated, but she was sent home "to give the treatment time to work." Two days later she was readmitted with peritonitis and died. Two patients in this group developed peritonitis after procedures, but the diagnoses were made late and the absence of appropriate medical records suggested inattention by ward staff. In a further five cases diagnosis, and therefore effective treatment, was unnecessarily delayed. For example, it took 22 days to diagnose a liver abscess in a 62 year old man who presented with fever of unknown origin: he died after attempted aspiration. In the last two cases a satisfactory diagnosis was not made. A man aged 62 with known chronic pancreatitis and osteoporosis developed intractable abdominal pain with loss of weight. This was ascribed to pain from vertebral collapse despite abnormal biochemical test results. In the last month of his life the patient developed a spastic paraplegia, the signs of which were clearly documented by a senior house officer but ignored by more senior staff. The certification of death from bronchopneumonia might have been more illuminating if help had been obtained from a neurologist.

\section{Carelessness or major incompetence}

There were 13 cases of major errors. In eight of the cases clinicians showed lack of care in management (five cases), failed to monitor carefully (two cases), and failed to answer a nursing request (one case). For example, a man aged 58 was admitted to a large city hospital after passing three melaena stools. His blood pressure was $110 / 60 \mathrm{~mm} \mathrm{Hg}$ (previous recording $150 / 90 \mathrm{~mm} \mathrm{Hg}$ ), his pulse rate was 88 beats $/ \mathrm{min}$, and his haemoglobin concentration was $98 \mathrm{~g} / \mathrm{l}$. He was not seen by experienced middle grade staff, he was not given fluid intravenously, his condition was not monitored, and his blood was not cross matched. Twelve hours later, in the middle of the night, he had a large haematemesis followed by a cardiorespiratory arrest, from which he died. In the other five cases the medical mishap was due to major clinical incompetence. For example, a surgeon who had no NHS appointment undertook intrathoracic fundoplication of the stomach in a 42 year old man with a hiatus hernia. The patient recovered from the operation but a few days later developed severe retrosternal pain caused by necrosis of the fundus of the stomach. There was a substantial delay before the patient was referred to and rescued in the local thoracic surgical unit.

\section{IDENTIFICATION OF FAULT}

In the NHS, consultants must take responsibility for all errors. In practice, however, junior staff often work independently and have to recognise when a problem exceeds their capability. In fact only 12 of the 56 faults in clinical practice were made by junior staff working on their own; in 26 cases consultants were primarily or solely responsible, and in a further 17 they appeared to have been aware that a problem existed but failed to focus on it (table III). It was also possible to identify cases in which the errors occurred either because doctors failed to recognise the need for specialist help (table IV) or because a specialist failed to recognise pathology outside his or her area of expertise or failed to take a sufficiently broad view (table V).

\section{AVOIDANCE OF MISHAP}

In most cases it was possible to identify how the mishap could have been most easily avoided. In 28 cases this was simply a matter of care: in clinical evaluation (seven cases), in carrying out a procedure 
TABLE III-Doctors involved with 56 claims of negligence where clinical fault found. Figures are numbers of cases

\begin{tabular}{|c|c|c|c|c|}
\hline \multicolumn{2}{|l|}{ Fault } & Consultant & $\begin{array}{l}\text { Non- } \\
\text { consultant }\end{array}$ & Team \\
\hline \multirow{6}{*}{\multicolumn{2}{|c|}{$\begin{array}{l}\text { Poor communication } \\
\text { Isolated error } \\
\text { Competence exceeded } \\
\text { Poor judgment } \\
\text { Poor teamwork } \\
\text { Carelessness or incompetence }\end{array}$}} & 6 & 1 & \\
\hline & & 10 & $5^{\star}$ & \\
\hline & & & $5 \dagger$ & \\
\hline & & 3 & & \\
\hline & & $4 \ddagger$ & $3 \neq 5$ & 68 \\
\hline & & 3 & 4 & $6 \$$ \\
\hline \multicolumn{5}{|c|}{$\begin{array}{l}\text { *In two cases consultant was involved. } \\
\text { In four cases consultant was available. } \\
\text { †Doctor primarily responsible failed to communicate with team. } \\
\text { §Consultant was aware that problem existed. }\end{array}$} \\
\hline \multicolumn{5}{|c|}{$\begin{array}{l}\text { TABLE IV-Clinical errors that could have been solved with specialist } \\
\text { help }\end{array}$} \\
\hline \multicolumn{2}{|c|}{$\begin{array}{l}\text { Patient's sex } \\
\text { and age } \\
\text { (years) }\end{array}$} & Error & & \\
\hline M 66 & \multicolumn{4}{|c|}{ Amoebic colitis treated as ulcerative colitis; inadequate } \\
\hline M44 & \multicolumn{4}{|c|}{$\begin{array}{l}\text { Aortic stenosis misdiagnosed as alcoholic cardiomyopathy; } \\
\text { alternative cause of heart failure not sought, and patient died }\end{array}$} \\
\hline M64 & \multicolumn{4}{|c|}{$\begin{array}{l}\text { Fever of unknown cause finally found to be due to liver } \\
\text { abscess; long delayed investigation, and patient died }\end{array}$} \\
\hline M62 & \multicolumn{4}{|c|}{$\begin{array}{l}\text { Chronic abdominal pain, weight loss, and paraplegia } \\
\text { inadequately investigated; patient died with a death certificate } \\
\text { diagnosis of bronchopneumonia }\end{array}$} \\
\hline F29 & \multicolumn{4}{|c|}{$\begin{array}{l}\text { Hodgkin's disease diagnosed as anorexia nervosa; no } \\
\text { laboratory or radiological investigations }\end{array}$} \\
\hline F50 & \multicolumn{4}{|c|}{$\begin{array}{l}\text { Septicaemia secondary to cellulitis; inappropriate } \\
\text { investigations and management; patient died }\end{array}$} \\
\hline F67 & \multicolumn{4}{|c|}{$\begin{array}{l}\text { Coeliac disease; repeated treatment with iron and folic acid } \\
\text { without attempt to find cause; patient lost } 32 \mathrm{~kg} \text { in seven years }\end{array}$} \\
\hline
\end{tabular}

TABLE V - Clinical errors made by specialists

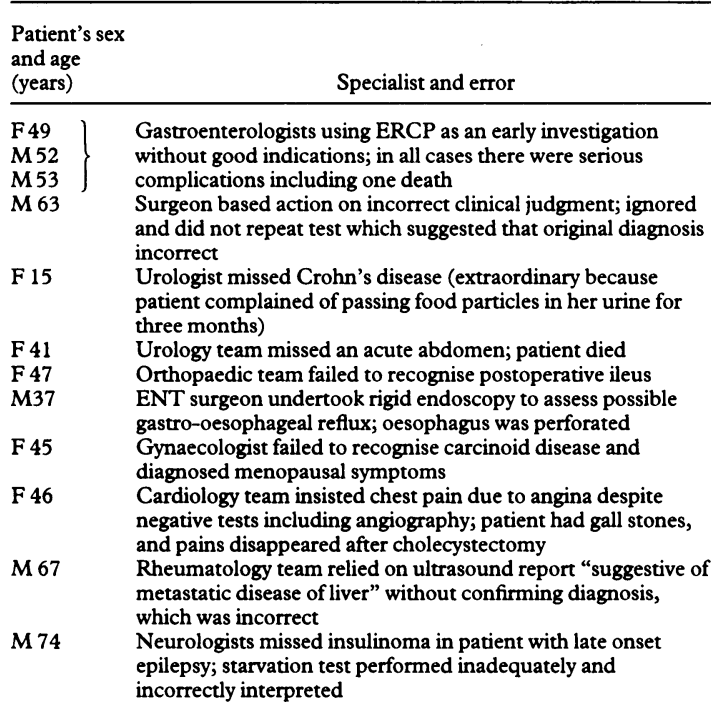

ERCP-endoscopic retrograde cholangiopancreatography. ENT = ear, nose, and throat.

(14 cases), or in assessing a patient after a procedure (seven cases). In five cases a clinician failed to recognise that a patient was seriously ill, and in a further six there was a breakdown in communication between patient and clinician. In only 10 cases was there need for further investigation to establish a diagnosis or future management. Even in these instances a quite simple manoeuvre would have set the clinician on the right track: checking the markers of inflammatory pathology in four cases; asking for ultrasound investigation in two cases; taking biopsy specimens in two cases (one to test a diagnosis of coeliac disease and one to determine the cause of a hyperechoic liver on ultrasonography); performing a ventilation perfusion scan to find the cause of a patient's breathlessness after surgery; and performing a barium meal examination of the small intestine in a patient with recurrent colicky abdominal pain.
ROLE OF AUDIT

It was not possible to determine how many of the cases were subject to audit, which is intended to provide internal quality control. ${ }^{7}$ In 10 cases (eight in which there was clinical fault) there were admissions of error with apology. In three cases there was evidence of review, but in each instance the conclusion was defensive rather than constructive. For example, a woman aged 39 collapsed with abdominal pain, and the admitting house officer diagnosed biliary colic. She was admitted to a ward, and the diagnosis was accepted by more senior staff apparently without examination of the abdomen or of the available radiographs. After 48 hours the patient died of peritonitis secondary to a perforated duodenal ulcer. The discharge letter stated: "We have reviewed our care in our audit and could find nothing to explain why she deteriorated so rapidly."

\section{Discussion}

The findings in this study differ considerably from those of Hawkins and Paterson, who analysed 100 cases in the West Midlands. ${ }^{8}$ Their analysis covered a wider spectrum of hospital practice but was retrospective and relied on medicolegal outcome. The cases which were resolved were all technical problems, mainly accidents during procedures. Thirty four of the cases were withdrawn, and the authors stated: "Many cases were debatable and lay in a grey area, where it was difficult to decide whether or not negligence had occurred."

My study was based on reports prepared for solicitors acting on behalf of patients (98 cases) or health authorities (two cases) and reflects my special interest in gastroenterology and general medicine. The increasing number of requests over the past three years is probably because solicitors realised that I was prepared to provide a detailed report promptly. For each case I carefully analysed the evidence, sought the opinions of colleagues, and checked the appropriate literature.

This study shows the potential value of opinion based on clinical assessment rather than on medicolegal argument and reinforces the need for prompt investigation. In the United Kindom a medicolegal decision is rarely reached within three years of the incident. In contrast, the Swedish complaints system-with no fault compensation-resolves cases within six months. ${ }^{9}$ Classifying cases is open to debate, but it provides a basis on which to make suggestions for limiting mishaps in clinical practice.

\section{NEED FOR IMPROVED UNDERSTANDING}

In 44 cases the medical process appeared satisfactory, but claimants were aggrieved. Many did not understand the cause of problems even after a sympathetic yet objective report. These patients seemed to have little background knowledge, but this may improve with better teaching of science in schools, possibly with an emphasis on the nature of health and disease. Thirty four of the cases were related to complications during or after a procedure. Patients need more information, and pamphlets describing the nature of procedures and their risks may be helpful. ${ }^{10}$ Five cases involved drug reactions, and perhaps a health warning might be included with each prescription. This would remind patients to report new symptoms and make them realise that all drugs have the potential to harm. ${ }^{11}$

NEED FOR IMPROVED EXPLANATION OF MEDICAL MISHAPS

In this study nearly all the claimants were seeking compensation, but some also stated that they had been thwarted in attempts to learn what had happened. Regrettably, this may be so: systems of internal review 
are often inadequate, and proposals for better means of independent review need re-examination..$^{811-13}$

\section{AVOIDANCE OF CLINICAL ERROR}

In 15 cases clinical errors were made during otherwise careful practice. In seven cases clinicians did not have an adequate diagnosis and either failed to consider other possibilities or failed to undertake simple screening tests. Doctors should be more willing to get second opinions on patients failing to make expected progress. A further eight cases were due to procedural accidents which would not have occurred if more care had been taken or if the operator had sought assistance. Most worrying are the 21 cases in which overall practice was not tightly controlled. This may reflect the relatively poor staffing ratios in British hospitals, but it is difficult to comment without more information.

RECOGNITION OF POOR STANDARDS OF CARE

An unacceptable standard of care was found in 13 cases. In seven cases staff failed to realise that a patient was seriously troubled and did not provide adequate follow up or additional help. In these cases the clinical notes were often inadequate. In six cases (all diagnostic errors) experienced doctors failed to recognise straightforward clinical problems that might be covered in higher specialist examinations. In two of these cases no attempt was made to provide a definitive diagnosis, and in another two cases specialists cut corners and failed to take note of the results of investigations that provided correct diagnoses. In two cases general physicians allowed patients to deteriorate for several days when they should have realised that the original diagnoses were inadequate. The medicolegal process will almost certainly fail to resolve most of these cases. The need for a satisfactory means of determining accountability and developing some system of sanctions seems inescapable.

IMPLICATIONS FOR HOSPITAL PRACTICE

In this study about three quarters of the clinical faults might have been avoided by better care. The trend towards increasing specialisation may not reduce the incidence of mishaps (tables IV and V). The Calman proposals for specialist training will reduce the period of general training. ${ }^{14}$ This, together with the declining role of general physicians and general surgeons, will lead to further changes in medical practice. It will be increasingly necessary to include several specialists in the care of complex cases. In 24 of the cases (including 19 where there were serious faults) incorrect management might have been avoided if the problems had been discussed with laboratory specialists or radiologists.

\section{ADVERSE EFFECTS OF LITIGATION}

It has been suggested that increasing litigation may lead to risk avoidance (doctors avoiding specialty work that includes high risk procedures), risk reduction (usually by overinvestigation), and disenchantment with quality assurance (audit) and so to a reduction in health care. ${ }^{15}$ In this series a third of claimants indicated that they would have been prepared to accept risks if these had been carefully explained. This would nullify the first assertion. Secondly, there is no evidence that more detailed expensive investigation would have protected patients from mishap.

On the other hand, doctors may be reluctant to participate in audit procedures which are not exempt from possible litigation. ${ }^{15}$ Litigation also has financial consequences for health care now that hospital authorities have assumed responsibility for legal liability. ${ }^{16}$ In this study $95 \%$ of the claimants had legal aid, and many potential claimants are probably inhibited by the cost of medicolegal investigation. Thus, there is a need for a system to investigate clinical complaints expeditiously and a means of compensation that will not be unreasonably expensive.

\section{CONCLUSION}

The future of the medical complaints system in the United Kingdom awaits the outcome of the official inquiry under Professor Alan Wilson. ${ }^{17}$ It is not clear whether his committee will leave the medicolegal process intact, but this study highlights the problems which need to be addressed. Whatever is decided, it is important that clinical errors are squarely faced and that the flow of money from care to compensation is minimised.

I thank my colleagues in the Addenbrooke's Health Trust for helpful discussions, especially the non-consultant staff who participated in the assessment of one particularly problematical case.

1 Letter from Westminster: Complaints process must put patients first. $B M$ 1993;307:12.

2 BMA. No fault compensation. London: BMA, 1987.

3 Royal College of Physicians. Compensation for adverse consequences of medical intervention; a report of the Royal College of Physicians. London: RCP, 1990.

4 Buck N, Devlin HB, Lunn JM. The report of a confidential enquiry into perioperative deaths. The Nuffield Provincial Hospitals Trust and King's Fund for Hospitals, 1987.

5 Department of Health and Social Security. United Kingdom reports on confidential enquiries into maternal deaths 1985-87 and 1988-90. London: HMSO, 1991.

6 Smith R. The epidemiology of malpractice. BMF 1990;301:620-1.

7 Department of Health. The quality of medical care. Report of the standing medical advisory committee for the secretaries of state for health for England and Wales. London: HMSO, 1990.

8 Hawkins C, Paterson I. Medico-legal audit in the West Midlands Region: analysis of 100 cases. $B M \mathcal{Y}$ 1987;295:1533-6.

9 Rosenthal MM. Dealing with medical malpractice: the British and Swedish experience. London: Tavistock Publications, 1987.

10 Segest E, Petersen F. Evaluation of the physician's obligation to provide information in Denmark. Med Law 1988;7:141-9.

11 Vere DW. The ethics of adverse drug reactions. Adverse Drug Reaction Bulletin 1988;128:480-3.

12 Havard J. "No fault" compensation for medical accidents. Med Sci Law 1992;32:187-98.

13 Segest E. Patients' complaints: the disciplinary system regarding evaluation of physicians' conduct. Med Sci Law 1993;33:41-76.

14 Department of Health. Hospital doctors: training for the future. The report of the Working Group in Specialist Medical Training. London: DoH, 1993.

15 Black N. Medical litigation and the quality of care. Lancet 1990;335:35-7.

16 Havard J. Doctors and medical negligence. BMf 1990;300:343-4.

17 NHS complaints reviewed by government order. $B M 7$ 1993;306:1711.

(Accepted 22 September 1993) 